\title{
IMAGEN Y EDUCACIÓN. MARKETING, COMERCIALIZACIÓN Y DIDÁCTICA. (ESPAÑA, SIGLO XX)
}

Por Pedro Luis Moreno y Antonio Viñao (coords). Madrid: Ediciones Morata, 2017, 248 páginas. ISBN 9788471128522.

\section{UN ENCUENTRO FRUCTÍFERO ENTRE LA HISTORIA DE LA EDUCACIÓN Y LOS SIGNIFICADOS CULTURALES DE LAS IMÁGENES}

Durante mucho tiempo las imágenes tuvieron unos usos muy acotados en el ámbito de la Historia. Además de la especificidad que algunas de ellas tenían como piezas sublimes en la Historia del Arte, donde se desarrollaron metodologías específicas para su descripción y análisis, para los demás historiadores, aquellas imágenes que mostraban algún aspecto del pasado, no eran sino un recurso para ilustrar visualmente alguna cuestión que se desarrollaba en el texto historiográfico y que la imagen elegida oportunamente corroboraba. Bastaba un simple comentario al pie de la imagen para afirmar lo que se mostraba, sin que hubiera, como en las fuentes escritas, el más mínimo trabajo crítico sobre el origen de las imágenes convenientemente rescatadas para reforzar los argumentos textuales. Por supuesto, cualquier imagen proveniente del pasado y conservada en algún archivo, museo u otras instituciones documentales, tampoco se la consideraba por parte de los historiadores como un texto visual, dotado con una estrategia discursiva en el que, con herramientas diferentes a las escritas, era posible entender una argumentación que estaba enmascarada por el poderoso artificio realista que presenta cada representación visual más allá de su simple apariencia.

Es justo decir que algunas escuelas historiográficas estaban contemplando las imágenes como un fenómeno cultural, en ocasiones con 
orientaciones antropológicas, y que las intentaban explicar más allá de los parámetros establecidos en la Historia del Arte. Así lo hicieron autores como Ernst Gombrich, ${ }^{1}$ que supo explicar posiciones iconográficas partiendo de representaciones elaboradas en diversos contextos culturales, o David Freedberg, ${ }^{2}$ intentando entender las complejas relaciones entre las imágenes y las personas, o la extensa obra de Roman Gubern, ${ }^{3}$ en torno a las múltiples características que presentan las imágenes y sus relaciones con el ethos humano y con las manifestaciones culturales donde han operado. Es cierto también que las imágenes comenzaron a interesar de diversos modos a otras disciplinas, que se han interrogado por los mecanismos entre percepción visual y conocimiento, un campo que ha ido creciendo con los avances y hallazgos de la neurociencia, y que explican cada vez con más detalle los mecanismos de percepción visual que tenemos los humanos, y lo que hay en ellas de cultural o de fisiológico. ${ }^{4}$

Que la Historia comenzase a preocuparse por las imágenes de otro modo al tradicional, es el resultado de diversos caminos que se han

\footnotetext{
${ }^{1}$ Ernst Gombrich historiador del arte, es uno de los más conocidos representantes de la escuela iconográfica alemana. En sus obras intentó siempre analizar las imágenes en capas significantes, yendo en su interpretación más allá de las dimensiones estéticas que presentan, intercalando análisis de sus funciones sociales y comunicativas. De su extensa producción destaco dos obras: La imagen y el Ojo (Madrid: Alianza Forma 1987; edición original inglesa de 1982). Aunque sin duda la mejor representación de su trabajo y pensamiento lo encontramos en Gombrich Esencial (Barcelona: Debate, 1999; (edición original inglesa de 1996). Se trata de una cuidada y representativa recopilación de textos en torno al arte, la representación y la cultura editada por Richard Woodfield.

${ }^{2}$ David Freedberg, El poder de las imágenes (Madrid: Cátedra, 1992; edición original norteamericana de 1989). Como ya advierte Freedberg en el prefacio de la obra: «Este libro no trata de la historia del arte. Trata de las relaciones entre las imágenes y las personas a lo largo de la historia».

${ }^{3}$ Roman Gubern es una figura reconocida e indiscutible sobre la Historia de las Imágenes y sus múltiples interrelaciones con la cultura y la sociedad. Sus trabajos parten de una perspectiva comunicativa siempre rica en significados por las extensas conexiones culturales que despliega en sus análisis. Es difícil resumir en una obra el trabajo del profesor Gubern. Su último libro Dialectos de la Imagen (Madrid: Cátedra, 2017) es un excelente ejemplo de su conocimiento de las imágenes en su encuentro con lo humano. Una de los mayores valores de su obra es la combinación entre amenidad y rigor profundo.

${ }^{4}$ La indagación de cómo recibimos, interpretamos y damos sentido a las imágenes es un campo en continuo crecimiento donde la neurocirugía y otras especialidades están dando respuestas y creando un debate que no está del todo consensuado todavía. Destaco dos trabajos esenciales e introductorios a una materia compleja: Imagen y Conocimiento, eds. Horace Barlow et alii (Barcelona: Crítica 1990; edición inglesa de 1986), recopilación de los trabajos discutidos en un encuentro en la Royal Society de Londres, y el libro de Donald D. Hoffman, Inteligencia visual. Como creamos lo que vemos (Barcelona: Paidós, 2000; edición original inglesa de 1998).
} 
ido trazando en las últimas décadas, y que han logrado cambiar los usos funcionales que tuvieron en el trabajo histórico. Un buen ejemplo ha sido el caso de la fotografía, una tecnología aparecida en 1839, en un momento en el que el positivismo se estaba desplegando como filosofía de concepción de la realidad, aunque hubo que esperar hasta 1937 para que las imágenes fotográficas comenzasen a entrar en los museos como imágenes artísticas con un autor reconocido como tal. ${ }^{5}$ En el caso español, la valoración cultural de las imágenes fotográficas es relativamente reciente; los primeros trabajos históricos están fechados en 1981, ${ }^{6}$ y los enfoques y contenidos han evolucionado conforme a los propios cambios que se han producido en la cultura occidental en las últimas décadas, estando ahora produciéndose trabajos de nuevos autores en la línea de las teorías posmodernas y de la reivindicación del microrrelato que, siguiendo las ideas de autores como Jean François Lyotard, ${ }^{7}$ niegan la historicidad a las fuentes fotográficas y a los problemas historiográficos que han sido recurrentes entre quienes nos hemos dedicado a la historia de y con la fotografía

\footnotetext{
${ }^{5}$ La historiografía en torno a la fotografía tiene dos etapas claramente diferenciadas. Durante el siglo XIX y las tres primeras décadas del siglo xx, se entendía que el devenir de ésta tecnología era el de sus avances ópticos, químicos y técnicos. El historiador de referencia de esta corriente historiográfica fue el profesor austriaco Josep Maria Eder, pero en 1937, en un momento en el que el fotograbado había llegado a un punto de desarrollo muy considerable, Beaumont Newhall primer conservador de fotografías del MOMA, de Nueva York, presentó una exposición en la que, por primera vez, el sujeto histórico fueron las imágenes fotográficas y sus autores con una metodología similar a la de la historia del arte. Véase al respecto el texto de Bernardo Riego sobre las influencias de ésta aproximación a la historia de las imágenes fotográficas en el texto: «De la "Escuela Newhall" a las "Historias" de la Fotografía: Experiencias y propuestas de Futuro", en Fotografía. Crisis de Historia, ed. Joan Foncuberta (Barcelona: Actar, 2002), 42-57.

${ }^{6}$ Sobre la historiografía fotográfica en España desde 1981, véase Bernardo Riego, «La historiografía española y los debates sobre la Fotografía como fuente histórica», Ayer 24 (1996): 91-111. Una revisión de la historiografía posterior, puede consultarse en el texto también de Bernardo Riego, «Una intersección de interpretaciones sobre fotografía: entre la disparidad metodológica y la diversidad de aproximaciones», Ayer 96 (2014), 185-199.

${ }^{7}$ Jean François Lyotard, La condición Posmoderna (Madrid: Cátedra, 1989; original francés de 1979). Aunque el autor ha renegado posteriormente de algunas de las afirmaciones de su trabajo, lo cierto es que ha tenido una enorme influencia en autores diversos, entre ellos algunos vinculados a la crítica fotográfica, que niegan que las imágenes fotográficas puedan ser una fuente válida para analizar el pasado. Un buen ejemplo de esa corriente de interpretación se resume en la afirmación de John Tagg en su libro The Burden of Representation (Minneapolis: University of Minnesota Press, 1988), 65: «Las fotografías nunca son prueba de la historia; ellas mismas son lo histórico». Algunas de las tesis que se están defendiendo en estos momentos en las Facultades de Bellas Artes de la universidad española trabajan con estos presupuestos conceptuales que están teniendo una enorme influencia entre los investigadores más jóvenes.
} 
con los métodos tradicionales de análisis, ya sea en historia del arte, ya sea en historia contemporánea. ${ }^{8}$

En el ámbito de la Historia de la Educación ha emergido en los últimos años un interés creciente por el estudio de las imágenes fotográficas como un elemento para entender aspectos de la dinámica de las aulas y los procesos educativos, lo que ha llevado a estos historiadores especializados a profundizar en las imágenes más allá de su mera apariencia realista. Sin ánimo de ser exhaustivos, el tiempo que ha transcurrido entre el seminario organizado por Bernat Sureda y Francisca Comás en la Universidad de las Islas Baleares en 2009, embrión del número monográfico en Educació i Història sobre «Fotografía e Historia de la Educación", ${ }^{9}$ y el reciente coloquio de Historia de la Educación centrado en las imágenes que tuvo lugar en septiembre de 2017 en El Escorial, ${ }^{10}$ es un arco temporal que engloba muy bien la labor de un numeroso grupo de historiadores de la educación para los que las imágenes están siendo objeto de atención, con algunos rasgos diferenciadores con otros colectivos de historiadores especializados en imágenes fotográficas que las estudian y abordan desde otros ámbitos. Además de las materias específicas de interés educativo en lo que muestran las imágenes, la Historia de la Educación está prestando atención de modo preferente a las propuestas de autores renovadores de los sujetos y las fuentes históricas como Peter Burke, ${ }^{11}$ o las reflexiones de W.J.T. Mitchel que se ha interrogado en torno al encuentro de las palabras y los textos escritos (tan esenciales en los procesos de enseñanza-aprendizaje) y el poder de las imágenes, dando

\footnotetext{
${ }^{8}$ Sin duda el trabajo más global en torno a la Historia de la Fotografía en España, comenzando por sus cuestiones metodológicas e historiográficas, es el del profesor de Historia del Arte de la Universidad de la Laguna, Carmelo Vega. Su obra Fotografía en España (1839-2015) historia, tendencias, estéticas (Madrid: Cátedra 2017) es un trabajo riguroso e imprescindible por la densidad y diversidad de cuestiones que plantea en sus novecientas páginas. Véase especialmente el capítulo «Las Historias de la Fotografía en España», pp. 19-76.

${ }^{9}$ Monográfico sobre «Fotografia i història de l’educació», Educació i Historia 15 (2010).

${ }^{10}$ XIX Coloquio de Historia de la Educación sobre Imágenes, discursos y textos en Historia de la Educación, Retos metodológicos actuales, organizado por la Sociedad Española de Historiadores de la Educación (SEDHE) y celebrado en El Escorial (Madrid) del 19 al 22 de septiembre de 2017.

${ }^{11}$ El libro de Peter Burke, Visto y no visto. El uso de la imagen como documento histórico. (Barcelona: Crítica, 2001; edición inglesa del mismo año), ha sido una de las obras que más ha contribuido a que muchos historiadores se preocupen por las imágenes desde una perspectiva más compleja que la mera ilustración. En ese mismo año, Ivan Gaskell abordaba elementos de la denominada Historia Visual en el libro editado por Peter Burke, Formas de hacer Historia (Madrid: Alianza 2001), 221-254).
} 
lugar a un paradigma que éste autor ha denominado El giro pictórico, o pictorial turn en su acepción original. ${ }^{12}$

\section{UNA OBRA CON CUATRO EJES VERTEBRADORES: DEL DOCUMENTO ICÓNICO AL MUSEISMO PEDAGÓGICO EN LAS CULTURAS ESCOLARES Y SUS MATERIALES EN LA HISTORIA DE LAS DISCIPLINAS ESCOLARES}

El libro que comentamos es el producto de un trabajo interdisciplinar elaborado por profesores y profesoras de la Universidad de Murcia, donde existe un núcleo investigador que está haciendo un espléndido trabajo sobre imágenes y educación con resultados tan notables como la exposición, en 2016, sobre «tarjeta postal ilustrada y educación» que reveló la enorme potencialidad que estas imágenes tienen para el estudio histórico, y cómo históricamente supieron cumplir diferentes funciones en el ámbito escolar, algunas desapercibidas hasta esta muestra que, en cierta medida, prefigura el libro que estamos analizando. ${ }^{13}$

Cómo apuntan en la introducción los coordinadores, Pedro L. Moreno Martinez y Antonio Viñao Frago, en el libro confluyen cuatro líneas de investigación fundamentales: se parte de la relevancia y la presencia que la imagen ha tenido en el mundo de la educación, aludiendo precisamente a «la importancia que la reciente renovación historiográfica ha atribuido a los documentos icónicos como fuentes del conocimiento para la investigación histórica», siendo el segundo eje las culturas escolares y los elementos que la conforman tanto los materiales como los inmateriales, que explican lo que ha sucedido en las aulas y los centros docentes, a los que se suman un tercer eje en torno a la historia de las disciplinas

\footnotetext{
${ }^{12}$ Debo confesar, con total honestidad intelectual, que no he seguido con anterioridad los trabajos de W.J.T. Mitchell respecto al giro pictorico y a los elementos de tensión entre la imagen y la palabra. Una lectura muy superficial por mi parte, me indica que estamos ante una propuesta muy interesante y sólida, que recoge en su interior algunos elementos de la semiótica estructural junto a otras aportaciones de la teoría iconográfica y sobre la dialéctica que se establece entre la enunciación textual y la representación visual y sus soluciones de poder e influencia en una sociedad hipervisiva como es la que transitamos. Los autores del libro objeto de esta recensión citan frecuentemente a este autor que necesita una lectura más profunda por mi parte, pero es evidente la influencia que tiene en este encuentro de la Historia de la Educación con las imágenes.

${ }^{13}$ Antonio Viñao, María José Martínez Ruíz-Funes y Pedro Luis Moreno (Comisarios) Tarjeta postal ilustrada y educación (España, siglos XIX-XX) (Murcia: Ediciones de la Universidad de Murcia, 2016), catálogo de la exposición.
} 
escolares y sus didácticas específicas, y un cuarto, que nos parece muy importante, el esfuerzo por preservar materiales de la memoria educativa, construyendo un museísmo pedagógico que proporcione sentido histórico a los objetos y a los fenómenos de los que ha quedado una huella que puede ser explorada en diversas direcciones.

El resultado del libro es muy satisfactorio porque la visión interdisciplinar de la que parte y la secuencia de las temáticas expuestas permiten una visión poliédrica en la medida que se van desplegando diversos aspectos del fenómeno iconográfico y sus relaciones con la Historia de la Educación.

Una de las cualidades más relevantes de éste libro es comprobar lo bien que se han engarzado las temáticas para que el lector interesado pueda ir leyendo de aspectos generales a cuestiones singulares que proporcionan una visión de conjunto cumpliendo las premisas que se enuncian en el título.

El libro comienza por un detallado estudio histórico de las tarjetas postales y su complejidad de funciones en el ámbito escolar, firmado por Antonio Viñao y María José Martinez Ruiz Funes, en el que se presenta el marco histórico y cultural de la difusión de la tarjeta postal ilustrada y como algunos establecimientos educativos las supieron usar como productos adscritos al gusto moderno y publicitar sus aspectos pedagógicos. El segundo capítulo, del que es autor Pedro L. Moreno Martínez, analiza los usos informativos y propagandísticos de imágenes escolares en la prensa de Murcia con motivo de las primeras experiencias en la región en 1907, de un modelo pedagógico — las colonias escolares-que tenía componentes integrales en la formación y atenciones sanitarias de los niños, dentro de las premisas innovadoras de la Escuela Nueva. De ese modo el fotoperiodismo constituye un sujeto de análisis histórico del que se extraen elementos significativos para la historia de la educación que van más allá de las meras inserciones periodísticas. Esta contextualización aparece de nuevo en el tercer capítulo dedicado a la educación popular y las Misiones Pedagógicas en Murcia en el que se hacen unas precisas reflexiones sobre la cultura visual y el alcance que tuvieron en dichas Misiones, en el caso de Murcia, con unas imágenes que ya no son meras ilustraciones, sino que revelan aspectos culturales que están en las representaciones de los diversos soportes que se estudian, ya sean pos- 
tales, ya sea prensa ilustrada. El profesor Pedro Luis Moreno lo explica muy certeramente en la página 85 de este capítulo:

Un estudio de esta naturaleza [se alude a las imágenes de las Misiones Pedagógicas referidas a Murcia] pone en evidencia, en primer lugar, el valor que estos fondos fotográficos tienen, [...] como patrimonio documental iconográfico, como testimonio histórico, estético y visual del pasado que representan. La recuperación y visibilización de un patrimonio hasta ahora, en gran medida, invisible y desconocido [...] al tiempo que contribuye a enriquecer las miradas de la historia, la interpretación de nuestro pasado.

El libro continua abordando el uso de fuentes visuales para entender la historia de la educación en Murcia, los cotos escolares y la enseñanza al aire libre, los catálogos de material escolar como fuentes para aproximarse a recursos y tecnologías del aprendizaje en el aula, cómo es el caso de los ábacos, la comparativa de catálogos, los cambios o la permanencia de los recursos didácticos ofrecidos, abriendo vías de análisis que conectan con toda la reivindicación cultural de los ephemera, materiales impresos de usar y tirar que, ahora revisados por los historiadores, hacen emerger otro conocimiento e inferir usos (y ausencias) que estos productos de imprenta proporcionan, a pesar de la corta vigencia que tuvieron cuando fueron editados.

En este sentido, el libro editado por Morata abre nuevos campos de interés al proporcionar estudios de larga duración (1924-1972) de catálogos de material de enseñanza y al ocuparse del marketing escolar en el capítulo 7, o del campo de las ilustraciones como complementos de aprendizaje a la enseñanza textual en los libros escolares, donde las imágenes publicadas tienen una eficiencia didáctica en la que hay que contemplar las dificultades técnicas de los grabados y sus costes y el empobrecimiento narrativo de las ilustraciones en los libros del franquismo. Pensamos, por ello, que este tipo de estudios abren caminos comparativos para observar los modelos de imagen publicitaria, por ejemplo, tan desarrollados en los años anteriores a la guerra civil, con sistemas tan depurados como el AIDA y sus translaciones más documentales a los libros de texto. Las ilustraciones escolares permiten estudiar la pervivencia de estereotipos en el capítulo 9, donde Raquel Sánchez, Laura Arias y 
Alejando Egea nos muestran la oportuna reinvención de la colonización española en América en base a recreaciones visuales y a verdades históricas cambiantes que muestran de modo diáfano la importancia de la coyuntura política nacional. Los últimos capítulos del libro se dedican a estudiar aspectos de los cuadernos escolares, tema que está siendo, en los momentos que escribo ésta recensión, objeto de una exposición en la Universidad de Murcia. ${ }^{14}$

Cómo historiador de las imágenes, creo que estamos ante un libro muy interesante, que abre caminos nuevos en la investigación de la Historia de la Educación con nuevos materiales no atendidos en el pasado por las razones que explicábamos al comienzo. No estamos ante una obra con trabajos iniciales o titubeantes en el uso de las imágenes como fuentes históricas, sino que los capítulos ofrecen unas reflexiones muy consolidadas conceptualmente que demuestran el fructífero encuentro entre las imágenes y los nuevos modos de comprender el pasado educativo con fuentes que llevan mucho tiempo esperándonos a los historiadores de todas las especialidades.

Bernardo Riego Amézaga Universidad de Cantabria briego@unican.es

\footnotetext{
${ }^{14}$ José Damián López Martínez, María José Martinez Ruiz-Funes y Encarnación Sánchez Jimenez (Comisarios), Los cuadernos escolares entre el texto y la imagen (Murcia: Ediciones de la Universidad de Murcia, 2017). Catálogo de la exposición.
} 